\title{
Analysis Utilizing AI Techniques for Optimum Performance at the Low Tension and The High Tension Line In BESS
}

\author{
Ajay Kumar Gupta \\ M.Tech. Scholar \\ IES College of Technology \\ Bhopal, Madhya Pradesh, India \\ ajaykumargpt587@gmail.com
}

\author{
Jyoti Bansal \\ Assistant Professor \\ IES College of Technology \\ Bhopal, Madhya Pradesh, India
}

\begin{abstract}
It has been a requisite for humanity to live since the electricity invented around an early 1900s. According to the electrical energy sector's economic constraints, power must be employed as quickly as practical after it is generated. Because storing large amounts of electrical energy is prohibitively expensive. However, as energy storage material becomes more accessible, dispersed production becomes more viable, especially with the Smart Grid concept.In this paper, we use the MATLAB SIMULINK platform to investigate a battery energy storage system (BESS). We used an effective algorithm, which is really a part of artificial intelligence (AI), to develop a controller for a converter system. The research focused on the low tension line (regional loads) and the high tension line (HV) after the grid connection, where the framework also compels the electrical desire and reactive loads.
\end{abstract}

Keywords: ESS, BESS, Micro-grids, Distribution Generators, Types of BESS, AI, THD

\section{INTRODUCTION}

The much more long-term strategy for reducing emissions the power industry is distributed generation involving renewable energy. A low voltage (LV) system with a cluster formation of distributed generators (DGs) and loads linked to DG integration is defined as micro-grid (MG). The Micro-Grids can be set to run in grid-connected or unbiased configuration. In MG, intermittent DGs (such as wind turbines (WT), photovoltaic (PV) generators, and so on) will cause a power supply and market discrepancy. As a result, frequency is a critical component of MG's smooth operation.Distributed generators are attracting numerous of researchers now a days. since the use of DG leads to minimize the waste of energy in the the PDS (power distribution system), also minimizes the variations in voltage levels, and many more are its advantages.

The ESS operation is categorized as follows in broad terms:
1. Getting charged in time span: This methodology is appropriate for using network electric power during off-peak intervals when electricity is considerably cheaper.

2. The charge - discharge timespan: An ESS's stored energy is used throughout peak periods. It must be remarked that system of electrical energy is currently more expensive, making the use of DGs more cost-effective. As a result, the primary justification for using an ESS system is to reduce or even eliminate the risks involved with renewable DG.The ESS operation is categorized as follows in broad terms:

1. Getting charged in time span: This methodology is appropriate for using network electric power during off-peak intervals when electricity is considerably cheaper.

2. The charge - discharge timespan: An ESS's stored energy is used throughout peak periods. It must be remarked that system of electrical energy is currently more expensive, making the use of DGs more cost-effective. As a result, the primary justification for using an ESS system is to reduce or even eliminate the risks involved with renewable DG.

The Battery Energy Storage System (BESS) is a framework that stores electric charge in specially designed batteries. The underlying principle is that some energy can be saved and used at a later time. Battery design process obtained from a vast state of science, turning the concept of a Battery Energy Storage System into a simple reality.

In most cases, a BESS is activated by a chemical reactions and electrical energy solution. overall ESS (Energy Storage Systems), in actuality, collect energy and information for later use.

These technologies include pumped hydro, air compressor storage, mechanical means flywheels, nowadays and BESSs. 
These systems subsidies differential renewable sources like wind, tidal, and solar power in an attempt to stabilize energy output and usage.

\section{LITERATURE REVIEW}

This study looks at the impact of placing BESS on a grid-level transmission system to support quick inertial frequency response. In three case studies, different simulation scenarios have always been run to evaluate the efficacy of using gridscale BESS to provide the proper inertial responsiveness to the grid. BESS has a high level of performance and qualities for providing this service, findings revealed. Three critical factors of BESS's upcoming use were suggested by the studies reviewed by (Alhejaj\& Gonzalez-Longatt, 2016).

The proposed MILP planning tool by (Mehrjerdi, 2019) employs a one-of-a-kind linear model for BESS that takes into account reactive power contributions as well as the flow limit. To improve the model's performance, it is also taken into account reactive power fluxes, bus voltages, and network losses. Aside from smoothing the voltage profile, the model's goals include lowering overall operating and planning costs.

The BESSs can be best designed in terms of cost reduction or voltage enhancement, depending on the planner's choices. The simulation results show that the voltage profile of the networking buses can be changed to some extent without significantly increasing the minimum cost.

This research looks at a flexible MPC-based optimization problem for a network of micro-grids, each of which has a hybrid energy supply, crucial, determining the possible loads, and energy storage systems. In addition, a microgrid adaptive controller architecture was developed by (Gbadega Peter \&Saha, 2020), in which power connections are established among microgrids as well as with the host grid.

The adaptive controller is primarily an enhanced MPC in used according that facilitates each EMU to provide either estimates and customized estimations connected to RESs energy production, local load demand, and selling prices more than a communications network throughout every run time. Even so, as microgrids are becoming more complicated, the traditional MPC depending EMS is becoming more challenging to adapt to various of scenarios. An efficient dimensioning technique for BESS in a smart microgrid with high PV protection and airconditioning assets is presented by(Xie et al., 2020) .
To reduce overall system costs, the proposed method includes two layers: a BESS preliminary dimensioning model and a BESS optimum dimensioning variant. The simulation results showed that now the ideal BESS dimensions could be achieved while retaining the original system cost low. In addition, the aggregator may be able to control the more accurate twoparameter air conditioners to reduce energy consumption. The energy assets of the microgrid have been carefully planned to handle large amounts of PV, reduce peak demand, and lower system expenses. The analysis in this article is dependent on a individual machine infinite-bus power system. It gives insight into the matter and provides a deep understanding, advising upcoming development in the specific situation of multimachine power systems. The investigation outlines the proposed methodological approach for a single-machine infinite-bus power system.

In this case, the proposed scheme by (Du et al., 2011) is very likely to the conventional damping torque assessment framework. But at the other hand, the recommend analytical procedure can easily be extended to the case of damping control using ESS to reduce energy oscillation over a transmission line in a multi-machine power system. The current project of (Koch-Ciobotaru et al., 2015) describes a generic method for incorporating RES power plants by employing SLBESS provide a PV power plant with a fluctuation blending provider.

Using used battery packs for this service is a more costeffective option than using inventive storage systems. Besides that, the optimization technique used here can be applied to an advanced battery system as well (first life). The recommend optimization model, which composed of reference measurements collected from a PV plant out over curriculum of a year, is used to achieve the ideal overall score for an SLBESS.

\section{METHODOLOGY}

Researchers are working on a number of modelling tools to represent various aspects of battery energy systems (BESS).

The functionality of single components is modelled using supervised or unsupervised strategies.

This section explains the basic simulation frameworks for a grid-connected battery system that is designed to perform an electric drive with reactive load at the $400 \mathrm{~V}$ load line. 


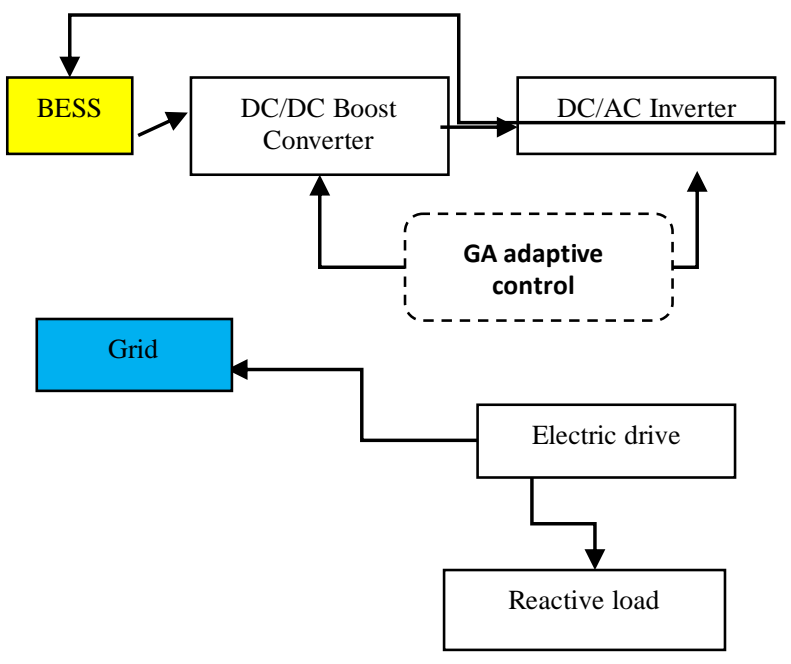

Figure 1 Block diagram of battery system implementation with AI switched regulatory compensator

The battery energy storage system (BESS) comprised of three basic parts: a battery, a power conversion system (PCS), and a battery management system controller (BMS). The battery packs and PCS are the structure's main electrical components, so both technologies are constantly developing. The basic framework of a BESS is shown in Figure 1. It consists of a battery that transmits DC power to the PCS, which converts it to $\mathrm{AC}$, and a transformer that adjusts the voltage to meet the needs of the utilities and loads. Both the battery packs and the PCS have their own control unit, which is the BMS.

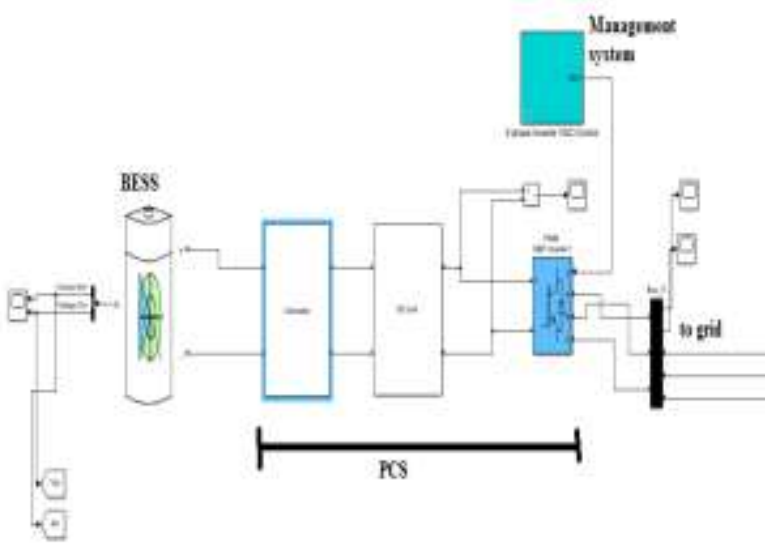

Figure 2 BESS model in simulation for analysis

This paper's inverter proceedure is a three-phase grid-connected Voltage Source Inverter (VSI) configuration that is commonly used in evenly distributed generating interfaces. A synchronised frame SVPWM regulator was used to control the inverter.Time calculations and arranging switches between first sector and all the others as detailed below:
Table 1 : Inverter Considerations

\begin{tabular}{|l|l|}
\hline Power electronic systems & IGBT/Diodes \\
\hline Snubbed resistance & $5000 \mathrm{ohms}$ \\
\hline Forward voltages & 0 \\
\hline Ron & $1 \times 10^{-3} \mathrm{ohms}$ \\
\hline
\end{tabular}

The GA variables were used to find the best and most optimal solution to the non-linear transcendental formulas that already existed. 50 people are in attendance. The number of iteration is 100 , and the crossover rate is 0.8 . a mutation rate of 0.01 . When a predefined number of iterations have been completed and the value delivered by the optimization problem has remained stable for a specified number of iterations while remaining below a threshold, the GA halts.

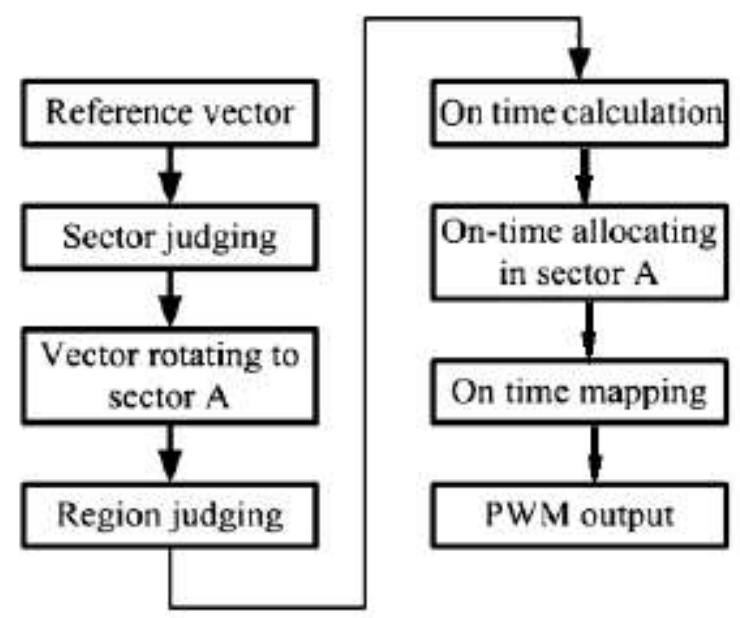

Figure 3 The three-level SVPWM calculation flow Computation created simpler

The upper-level optimization senses a group of power system failures (frequency and THD levels), while the lower-level optimization simulates the system operator's response to the upper-level outages.In the event of a crisis, the system operator serves as a mechanism to perform the power system. The design of the compensator stays constant, with the only variation being the device's control.

\section{RESUlTS AND DiscUSSIONS}

The device is powered by BESS battery storage energy and is then fed to the system, as well as being designed to power reactive loads and electric drives at the high tension line. The compensator was designed specifically for a battery energy 
storage system (BESS) that has a constant system output at $410 \mathrm{~V}$ and is utilised by two converters for whom the output is managed by a controller that is accompanied by a controller that is followed to maintain the voltage at the line and remediate the power factor in the system in order to drive a variety of loads. The system is driven by BESS battery storage energy and is then connected to the grid, as well as being developed to power reactive loads and electric drives at the high tension line.

After the controller was built using a rhythmic constrained genetic algorithm of AI learning, the control system was labelled HL GA. The front-end traditional converter model based on bridge converter innovation, accompanied by the battery energy storage system BESS incorporated with the grid, has been investigated for enhanced quality through the use of appropriate genetic assessment and genes variables for enhanced performance from the same infrastructure.

(System 1) BESS with PI-controlled converters that generate PWM signals

BESS with converters controlled by an HL GA-based control system (System 2).

CASE 1: BESS at the LV load side for a comparison of two designed controllers and their effectiveness prior to grid integration

The assessment of the system on the BESS's low voltage (LV) side with a line voltage of $410 \mathrm{~V}$ is the focus of this example. The system's aspects are assessed at the bus terminal after the converter, before it is connected to the grid system via transformers.

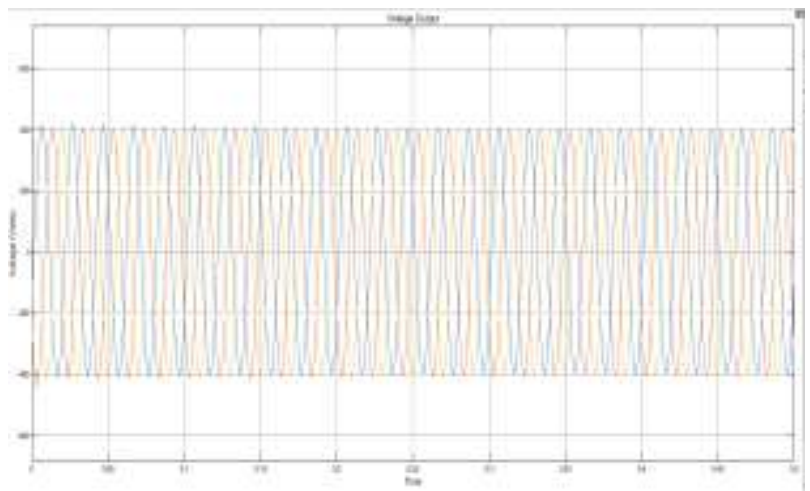

Figure 4 Voltage output from the converter driving loads prior to the grid integration in system 1

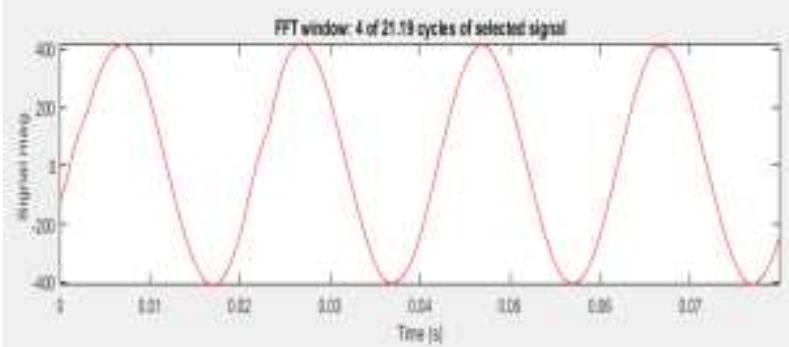

Figure 5 FFT investigation of Voltage output from the converter in LV line driving loads in system 1

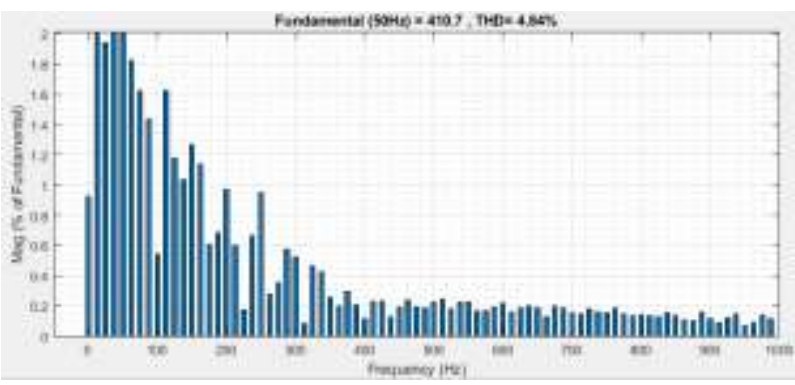

Figure 6 THD\% in Voltage output in LV line of system 1 driving loads

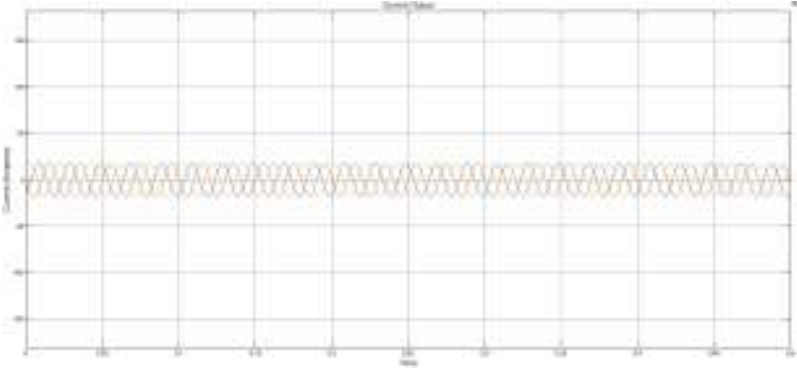

Figure 7 Current output from the converter driving loads before grid integration in system 1

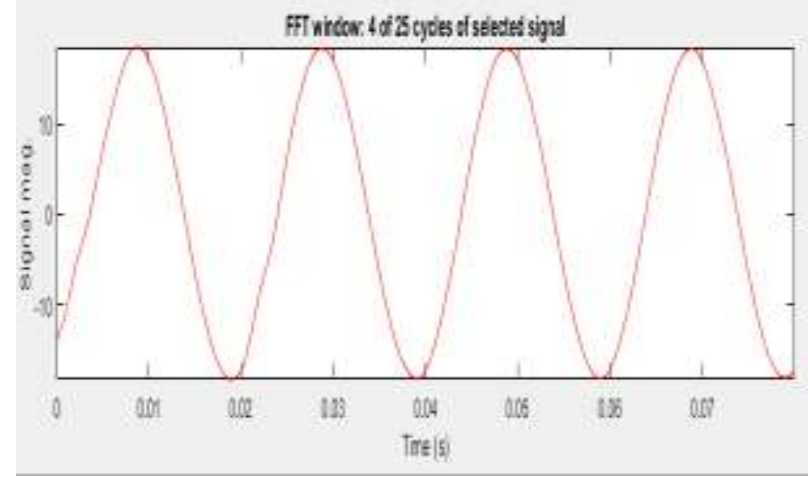

Figure 8 FFT analysis of current output from the converter in LV line driving loads in system 1 


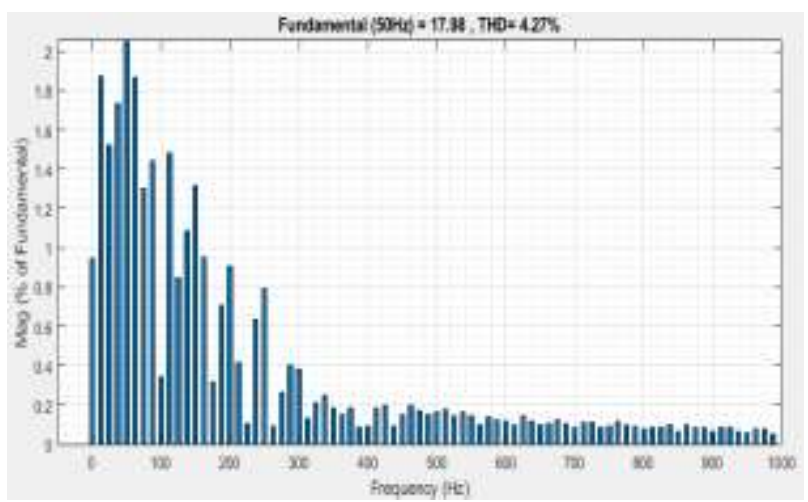

Figure 9 THD\% measured in current output from the converter in LV line driving loads in system 1

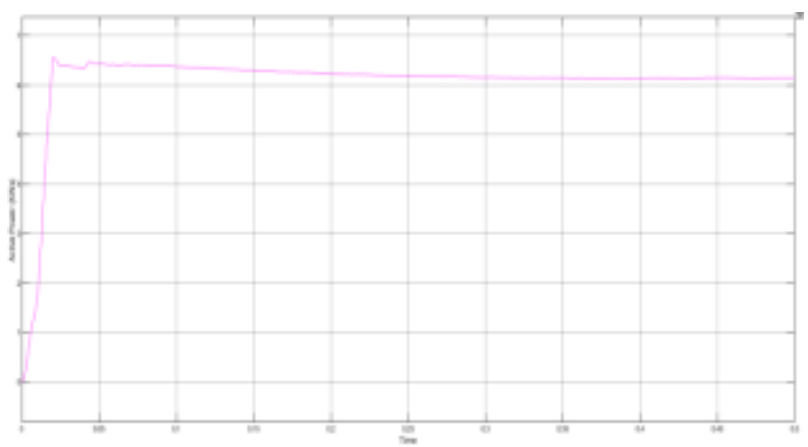

Figure 10 Active Power output in BESS system driving LV line loads having converters with control of system 1

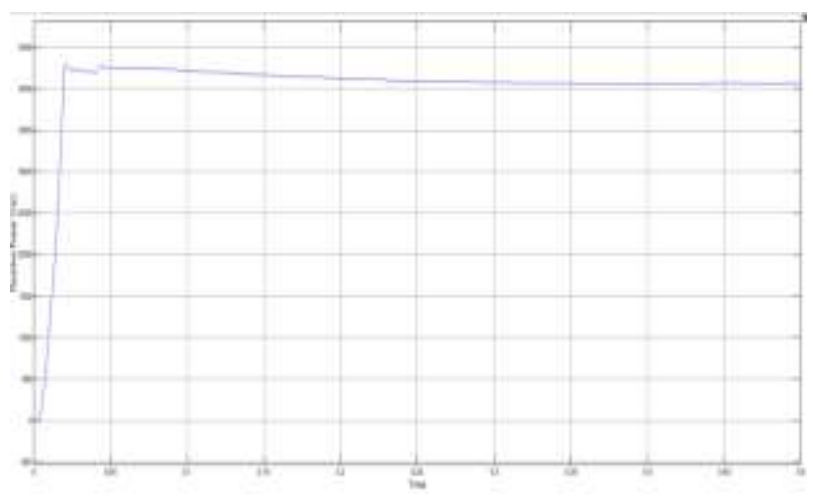

Figure 11 Reactive Power in LV line with converters having control as in system 1

LV line quality analysis using controllers in system 2 driving local loads

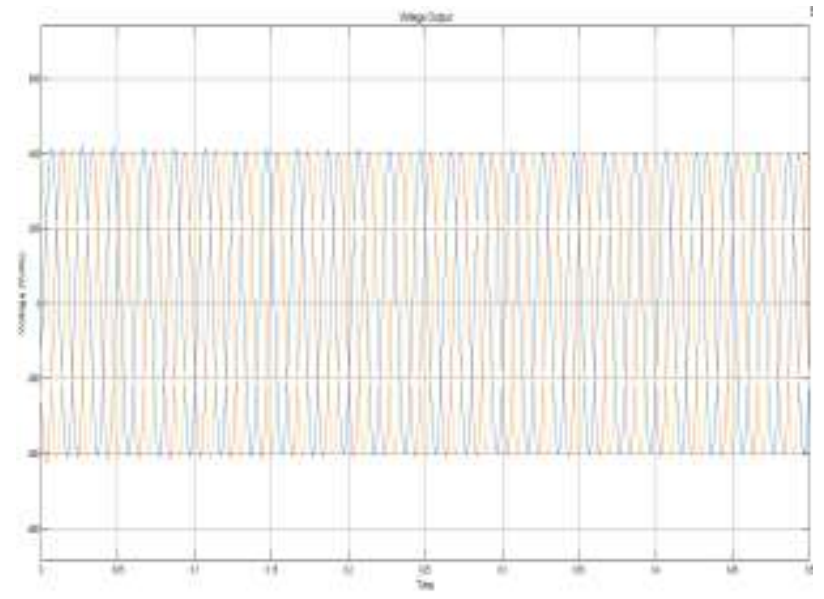

Figure 12 Voltage output from the converter driving loads before grid integration in system 2

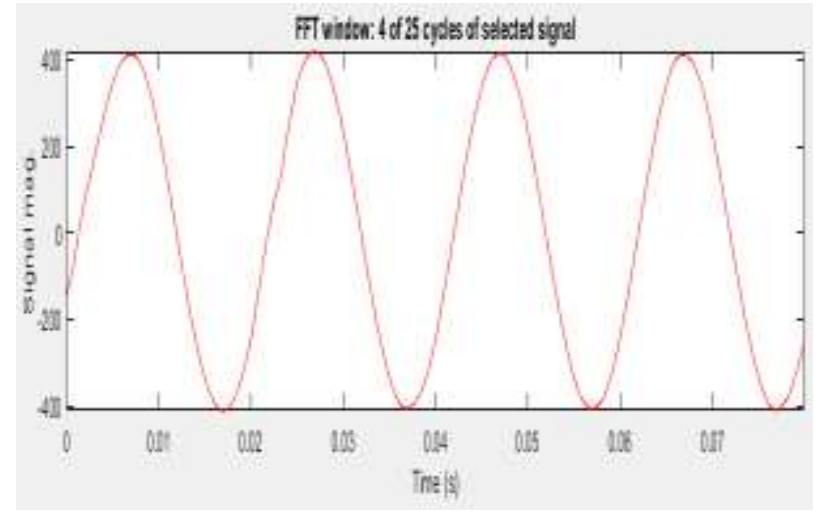

Figure 13 FFT analysis of Voltage output from the converter in LV line driving loads in system 2

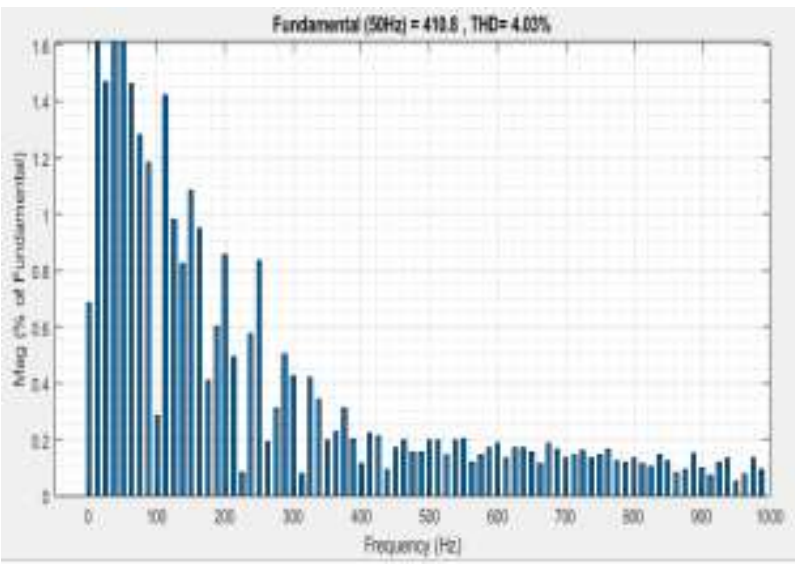

Figure 14 THD\% of Voltage output from the converter in LV line driving loads in system 2 


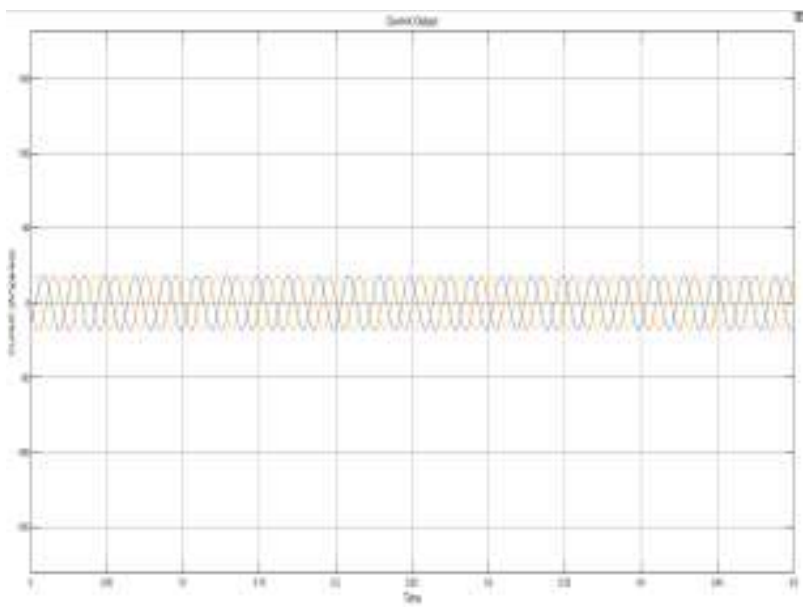

Figure 15 Current output from the converter driving loads before grid integration in system 2

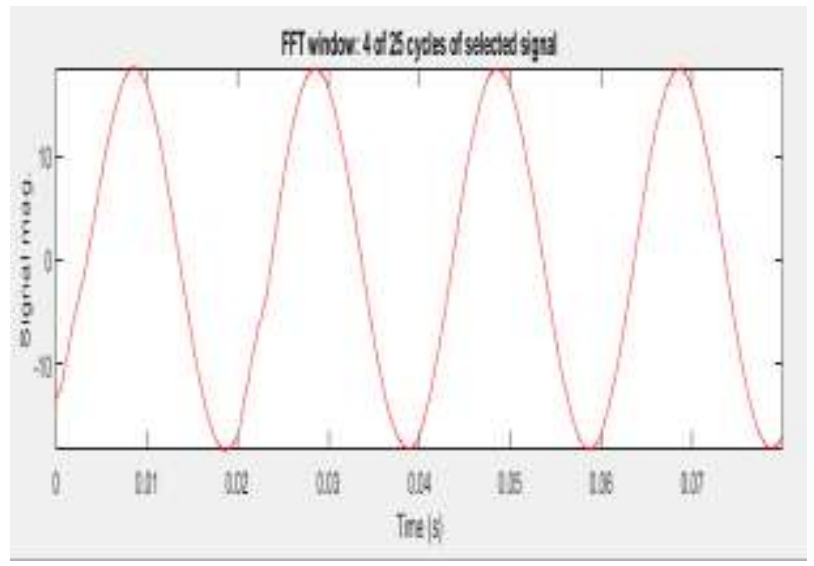

Figure 16 FFT analysis of current output from the converter in LV line driving loads in system 2

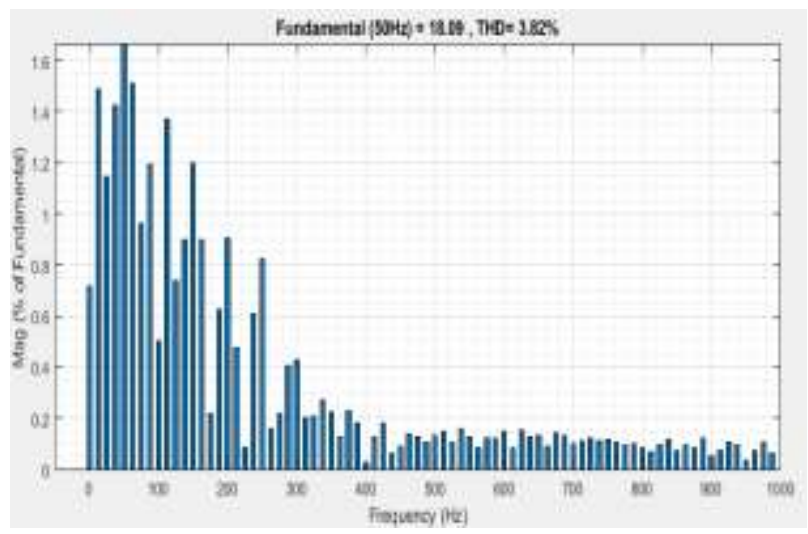

Figure 17 THD\% measured in current output from the converter in LV line driving loads in system 2

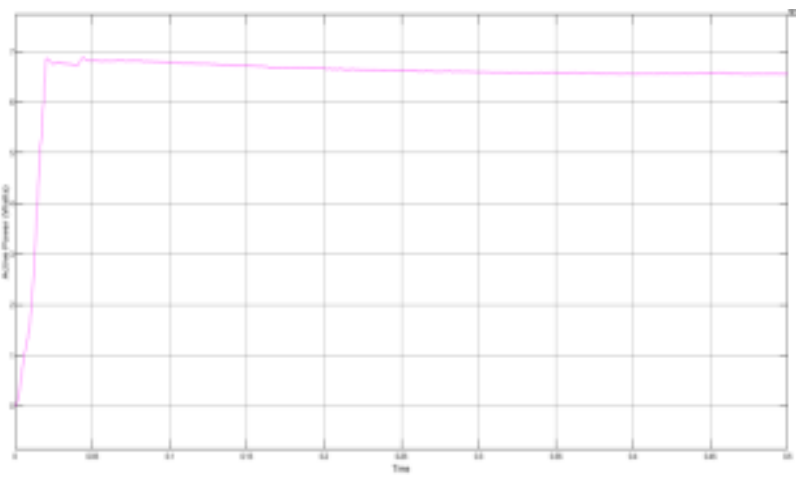

Figure 18 Active Power output in BESS system driving LV line loads having converters with control of system 2

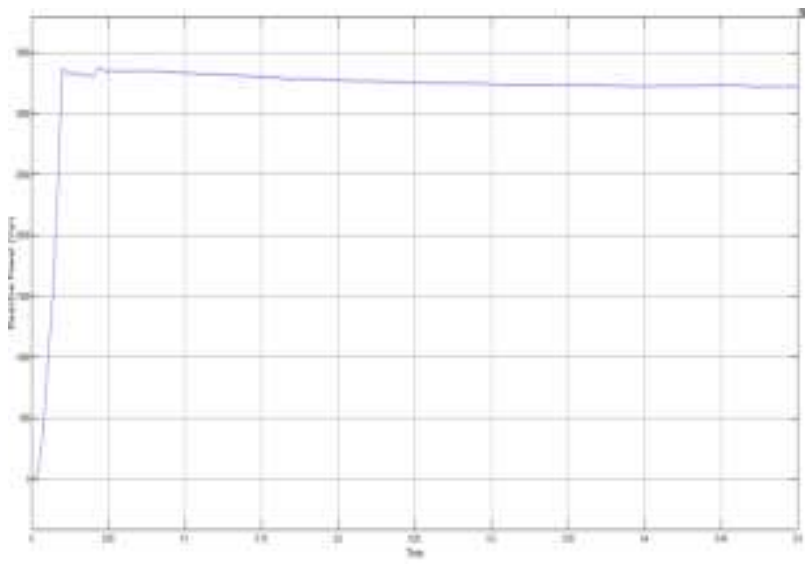

Figure 19 Reactive Power in LV line with converters having control as in system 2

\begin{tabular}{|l|c|c|}
\hline \multicolumn{3}{|c|}{$\begin{array}{c}\text { Table 2 Comparison of distortion factors at the low voltage line } \\
\text { of the BESS employing two controls for converters }\end{array}$} \\
\hline Factors/ Model & $\begin{array}{c}\text { System 1 } \\
\text { performance at the } \\
\text { LV line }\end{array}$ & $\begin{array}{c}\text { System 2 } \\
\text { performance at the } \\
\text { LV line }\end{array}$ \\
\hline $\begin{array}{l}\text { Active Power } \\
\text { (KWatts) }\end{array}$ & 6.142 & 6.565 \\
\hline Voltage (Volts) & 410 & 410 \\
\hline Current (Ampere) & 17.98 & 18.09 \\
\hline THD\% in voltage & 4.84 & 4.03 \\
\hline THD\% Current & 4.27 & 3.82 \\
\hline
\end{tabular}


CASE 2: Analyzing the impacts on the high voltage line driving heavy loads (electric drive and reactive load)

An $11 \mathrm{KV}$ high voltage line is used to supply two types of loads in this case: aggressive and customizable nature electric drives.

The investigation included both loads in the devices connected, as well as multiple converter control approaches, and the Total Harmonic Distortion Percentage at some of these load terminals was examined.

It is carried out to see how changes in the converter control scheme affect the HV line quality at the loading locations.

\begin{tabular}{|c|c|c|c|c|}
\hline \multirow[t]{2}{*}{ Factors } & \multicolumn{2}{|c|}{ System 1 in HV Line } & \multicolumn{2}{|c|}{ System 2 in $\mathrm{HV}$ line } \\
\hline & $\begin{array}{l}\text { Electric } \\
\text { drive } \\
\text { terminal }\end{array}$ & $\begin{array}{l}\text { Reactive } \\
\text { load } \\
\text { terminal }\end{array}$ & $\begin{array}{l}\text { Electric } \\
\text { drive } \\
\text { terminal }\end{array}$ & $\begin{array}{l}\text { Reactive } \\
\text { load } \\
\text { terminal }\end{array}$ \\
\hline $\begin{array}{l}\text { THD\% } \\
\text { voltage }\end{array}$ & 4.84 & 4.36 & 4.03 & 3.45 \\
\hline $\begin{array}{l}\text { THD \% in } \\
\text { current }\end{array}$ & 4.94 & 5.17 & 4.09 & 4.21 \\
\hline
\end{tabular}

The deformation stages of the current (I) ingested on the load terminals, which are expected to rise or fall in identity, are lowered using the controller on system 2 that is HL GA, according to previous data of THD percent estimation at the loaded terminals of two loads. THD levels in systems 1 and 2 range from 5.17 percent aggressive load point and 4.94 percent electric drive load to 4.21 percent reactive load point and 4.09 percent electric drive load. Variations in THD percent of voltage waveforms attainable at loading sites are also noticeable. Despite the minor distinction between the two systems, the controller that was assembled consistently proven to be a suitable solution for handling the inverter architectural features.

\section{CONCLUSION}

In this paper, we have used the MATLAB - SIMULINK platform to analyse a battery energy storage system (BESS). We used an optimal algorithm, which is a subfield of artificial intelligence, to construct a controller for a converter system.

The research focused on the low tension line (local loads) and the high tension line (HV) after the grid connection, where the framework also motivates the electrical drive and reactive loads. A 400V phase to phase load line's repercussions has been investigated. The independent inquiry will include a voltage and current analysis including the purpose of analysing the distortion level fluctuations that have established in the LV and HV lines when driving various loads with the proposed controller.

- In Case 1, the controller designed reduced current and voltage waveform distortions from 4.84 percent to 4.03 percent and 4.27 percent to 3.82 percent, respectively, when other waves were investigated at the LV line. The output of active power increased by about $6 \%$.

- The established genetic algorithm motivated converter control strategy diminished the THD percent in voltage and current waveforms across both terminals to 4.03 percent and 3.45 percent in voltage and 4.09 percent and 4.21 percent in current waveforms in Case 2 at the HV line.

\section{References}

1. Alhejaj, S. M., \& Gonzalez-Longatt, F. M. (2016). Investigation on grid-scale BESS providing inertial response support. 2016 IEEE International Conference on Power System Technology, POWERCON 2016. https://doi.org/10.1109/POWERCON.2016.7754049

2. Mehrjerdi, H. (2019). Simultaneous load leveling and voltage profile improvement in distribution networks by optimal battery storage planning. Energy, 181, 916-926. https://doi.org/10.1016/j.energy.2019.06.021

3. Gbadega Peter, A., \&Saha, A. K. (2020). Adaptive model-based receding horizon control of interconnected renewable-based power micro-grids for effective control and optimal power exchanges. 2020 International SAUPEC/RobMech/PRASA Conference, SAUPEC/RobMech/PRASA 2020. https://doi.org/10.1109/SAUPEC/RobMech/PRASA48453.202 0.9041136

4. Xie, C., Wang, D., Lai, C. S., Wu, R., Huang, J., \& Lai, L. L. (2020). Optimal Sizing of Battery Energy Storage System in Smart Microgrid with Air-conditioning Resources. 2020 IEEE International Smart Cities Conference, ISC2 2020. https://doi.org/10.1109/ISC251055.2020.9239044

5. Du, W., Wang, H. F., Cheng, S., Wen, J. Y., \& Dunn, R. (2011). Robustness of damping control implemented by Energy Storage Systems installed in power systems. International Journal of Electrical Power and Energy Systems, 33(1), 35-42. https://doi.org/10.1016/j.ijepes.2010.08.006

6. Koch-Ciobotaru, C., Saez-De-Ibarra, A., MartinezLaserna, E., Stroe, D. I., Swierczynski, M., \& Rodriguez, P. (2015). Second life battery energy storage system for 
enhancing renewable energy grid integration. 2015 IEEE Energy Conversion Congress and Exposition, ECCE 2015, 1, 78-84. https://doi.org/10.1109/ECCE.2015.7309672

7. Jinlei, S., Lei, P., Ruihang, L., Qian, M., Chuanyu, T., \&Tianru, W. (2019). Economic Operation Optimization for 2nd Use Batteries in Battery Energy Storage Systems. IEEE Access, 7 , $41852-41859$. https://doi.org/10.1109/ACCESS.2019.2902402

8. ZHAO, H., WU, Q., WANG, C., CHENG, L., \& RASMUSSEN, C. N. (2015). Fuzzy logic based coordinated control of battery energy storage system and dispatchable distributed generation for microgrid. Journal of Modern Power Systems and Clean Energy, 3(3), 422-428. https://doi.org/10.1007/s40565-015-0119-x

9. Liu, Y., BengGooi, H., \& Xin, H. (2018). Distributed energy management for the multi-microgrid system based on ADMM. IEEE Power and Energy Society General Meeting, 2018-January, https://doi.org/10.1109/PESGM.2017.8274099

10. Abusief, F., Caldon, R., \&Bignucolo, F. (2016). Remote islanded distribution networks supplied by BESS integrated PV generation units. EEEIC 2016 - International Conference on Environment and Electrical Engineering. https://doi.org/10.1109/EEEIC.2016.7555634

11. Bahloul, M., \&Khadem, S. K. (2018). Design and control of energy storage system for enhanced frequency response grid service. Proceedings of the IEEE International Conference on Industrial Technology, 2018-February, 11891194. https://doi.org/10.1109/ICIT.2018.8352347

12. Hong, M., Yu, X., Yu, N. P., \&Loparo, K. A. (2016). An Energy Scheduling Algorithm Supporting Power Quality Management in Commercial Building Microgrids. IEEE Transactions on Smart Grid, 7(2), 1044-1056. https://doi.org/10.1109/TSG.2014.2379582

13. Serban, I., \&Marinescu, C. (2013). Enhanced Control Strategy of Three-Phase. c.

14. Lee, H., Byeon, G. S., Jeon, J. H., Hussain, A., Kim, H. M., Rousis, A. O., \&Strbac, G. (2019). An Energy Management System with Optimum Reserve Power Procurement Function for Microgrid Resilience Improvement. IEEE Access, 7(c), 42577-42585. https://doi.org/10.1109/ACCESS.2019.2907120

15. Bajaj, M., Aggarwal, S., \& Singh, A. K. (2020). Power quality concerns with integration of RESs into the smart power grid and associated mitigation techniques. PIICON 2020
- 9th IEEE Power India International Conference. https://doi.org/10.1109/PIICON49524.2020.9113008

16. Li, X., Hui, D., Wu, L., \& Lai, X. (2010). Control strategy of battery state of charge for wind/battery hybrid power system. IEEE International Symposium on Industrial Electronics 1 , 2723-2726.

https://doi.org/10.1109/ISIE.2010.5637016

17. Hussain, J., Hussain, M., Raza, S., \& Siddique, M. (2019). Power quality improvement of grid connected wind energy system using DSTATCOM-BESS. International Journal of Renewable Energy Research, 9(3), 1388-1397.

18. Kim, K., Yoon, T., Byeon, G., Jung, H., Kim, H., \& Jang, G. (2012). Power demand and power quality analysis of EV charging station using BESS in MicroGrid. 2012 IEEE Vehicle Power and Propulsion Conference, VPPC 2012, 9961001. https://doi.org/10.1109/VPPC.2012.6422752

19. Lawder, M. T., Suthar, B., Northrop, P. W. C., De, S., Hoff, C. M., Leitermann, O., Crow, M. L., Santhanagopalan, S., \& Subramanian, V. R. (2014). Battery energy storage system (BESS) and battery management system (BMS) for grid-scale applications. Proceedings of the IEEE, 102(6), 10141030. https://doi.org/10.1109/JPROC.2014.2317451 